sightseer-the man or woman who "has never seen the moon through a telescope." This is scarcely possible with the present small staff, but if ways and means could be found it would be well worth while for other observatories to be among the subscribers to the corporation, if they could thereby transfer a part or the whole of their embarrassments from sightseers. It is worth remarking that the situation of the Norman Lockyer Observatory would probably attract this type of visitor, who naturally expects to climb a tower or a hill, and would not be disappointed. But we should prefer to lay stress on the more serious uses of the observatory.

\title{
The Oxford Expedition to Spitsbergen, I92I.
}

\section{Ornithological Observations.}

By the Rev. F. C. R. Jourdain (Leader of the Expedition).

A LTHOUGH the collections made by members of the expedition have not yet been worked out, it is now possible to form some idea of the extent to which our knowledge of the Spitsbergen group has been increased by the Oxford Expedition of rg2r. Owing to difficulties caused by industrial unrest both in England and Norway, the original plans had to be considerably modified, and it was agreed to carry out a biological survey of the southern half of Bear Island, with special reference to the ornithology, before proceeding to the west coast of Spitsbergen.

Practically no work of any importance in this field has ever before been undertaken by Englishmen, and no collections from here exist in any British museum. The only important works on the ornithology of this most interesting, but somewhat inaccessible, spot are Swenander's "Beiträge zur Fauna der Bären-Insel," published in the K. Svenska Vet-Akad. Handl., Bd. xxvi. (I900), and some passages in the great work of Koenig, "Avifauna Spitzbergensis" (I9II). Swenander visited Bear Island in I899, and recorded twenty-two speciès, while Koenig increased the number to thirty-six, but some of these rest on rather dubious evidence.

The northern half of Bear Island is flat, and covered with innumerable lagoons, but the southern half is hilly, and the coast line consists almost entirely of bold cliffs, which are the resort of millions of sea birds. It is this portion of the island which was investigated by the expedition. Two hitherto unrecorded breeding species were recognised in $192 \mathrm{I}$, and both cases are of great interest as filling up gaps in the distribution of the species concerned. Additions were also made to the list of casual visitors, but more important was the acquisition of a series of nearly eighty skins of breeding species and more than 300 eggs from the island. Equally valuable are the biological notes on the share of the sexes in incubation, the courtship and breeding habits, of which very little has been recorded in the case of these Arctic species.

Actual work on the Spitsbergen group did not begin until June 25. Here, again, it must be remembered that the latest English work on the ornithology of Spitsbergen is Mr. Trevor Battye's paper in the Ibis, 1897, pp. 574-6oo. No series of skins from here with any pretension to complete-

$$
\text { No. } 2709 \text {, vol. I08]. }
$$

ness exists in any British museum. The eggs of the Barnacle Goose have previously been taken by only one expedition, viz. that of Prof. Koenig in 1907 and 1908, and the twelve eggs then obtained were the only wild-laid eggs known to science till the present season, when twenty-two eggs were obtained by the Oxford Expedition.

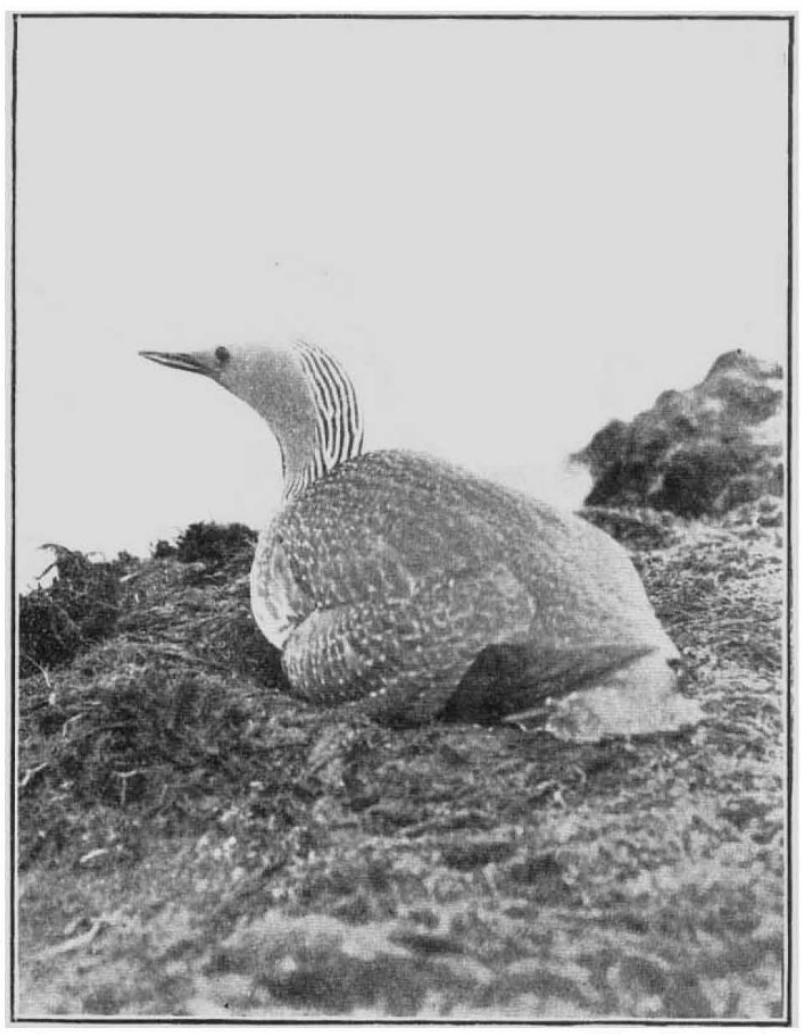

[Photo, Seton Gordon.

Fif. r.-Red-tbroated diver on nest.

Mr. J. S. Huxley's researches on the courtship of the Red-throated Diver (Colymbus stellatus) (Fig. I) and the Grey Phalarope (Phalaropus fulicarius) are referred to later, and need not be touched upon here.

In Mr. Trevor Battye's paper only twenty-nine species were recorded from all sources. Since then the total has been raised to fifty-three, and 
of these no fewer than thirty are now known with certainty to breed locally. Probably one of the most valuable results of the expedition will prove to be the additional light thrown on the breeding ranges of many northern forms. For example, in Koenig's great work only about seven definite occurrences of the Turnstone (Arenaria interpres) are recorded, of which two are also mentioned by Trevor Battye. Yet in 192 I not only were specimens actually obtained from two localities in Ice Fjord, but also about nineteen pairs were met with breeding in one restricted district on the north coast, and adults, young in down, and eggs were collected. This clears up the mystery of the distribution of this species, which is known to nest quite commonly in Greenland up to $82^{\circ} 30^{\prime}$ on the west side, as also in Novaya Zemlya; while up to the present no details of breeding in the Spitsbergen group have been available. Similarly the

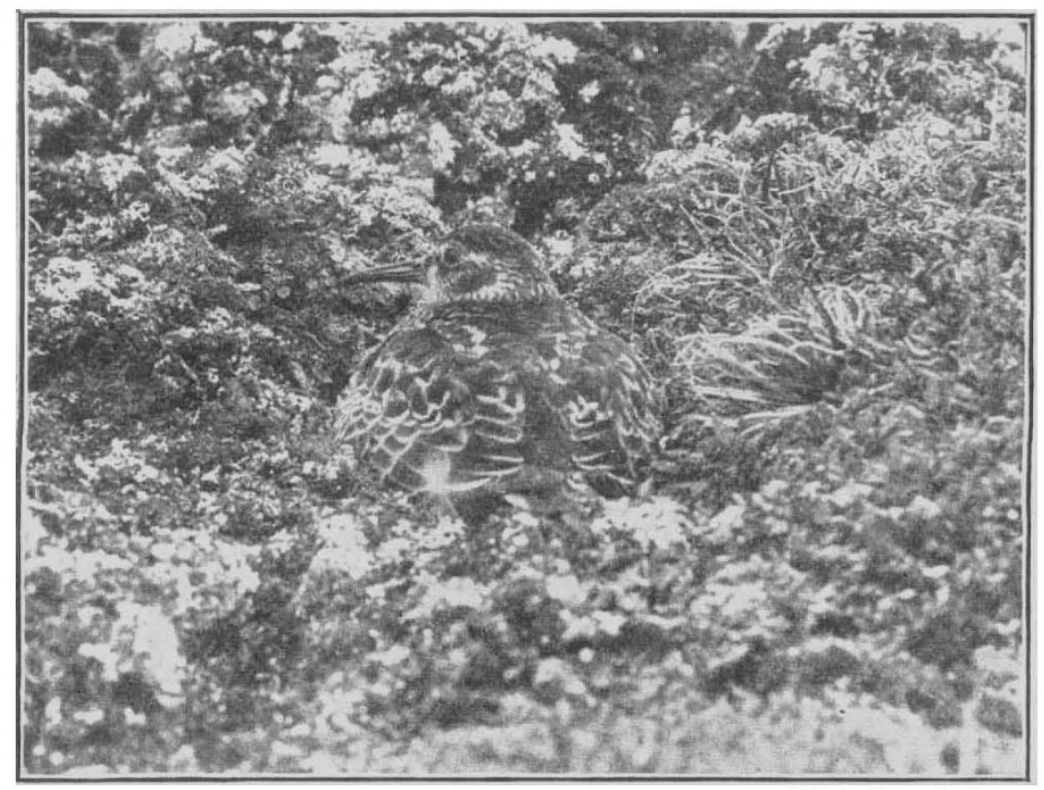

FIG. 2,-Purple sandpiper on nest.

Dunlin (Erolia alpina), hitherto known solely as an occasional visitor, has now been shown to breed in at least one district. Definite information as to the northern limit of the breeding grounds of the Ringed Plover (Charadrius hiaticula) and the nesting-range of the Barnacle Goose (Branta leucopsis) are also now available for the first time.

The skins obtained from Spitsbergen, nearly two hundred in number, are particularly interesting from the fact that they include a number of young birds in down plumage, such as Turnstone (Arenaria interpres), Grey Phalarope (Phalaropus fulicarius), Pink-footed Goose (Anser brachyrhynchus), Little Auk (Plotus alle), Glaucous Gull (Larus hyperboreus), and Brunnich's Guillemot (Uria lomvia), which are little known and not represented in most collections. Another valuable point is the NO. 2709 , VOL. IO8] presence of a large series of all the three species of geese which nest in the group in the flightless stage, thus furnishing excellent material for the study of the moults of these birds.

The eggs are of equal interest. In every case when a nest of any species of goose or duck has been taken the down and feathers have also been carefully collected. The eggs of Branta leucopsis have already been mentioned, but useful series of those of B. bernicla and Anser brachyrhynchus have also been taken. No eggs of the Puffin from Spitsbergen exist in collections so far as we are aware, and even Koenig's expedition failed to obtain any; but there are four in the Oxford Expedition's collection. Mandt's Guillemot (Uria grylle mandtii), Grey Phalarope (Ph. fulicarius), Purple Sandpiper (E. maritima) (Fig. 2), and Turnstone (A. interpres), are all represented in the collection, while two authentic clutches of eggs of the King Eider (Somateria spectabilis) are of especial value as furnishing trustworthy data for the description of eggs and down.

In one respect the expedition was unlucky. The Spitsbergen Ptarmigan (Lagopus hemileu curus) was absent in 1921 from several districts where it was plentiful in 1920. Feathers and droppings of the previous year were seen in hundreds; even fragments of last year's eggs were found, but the birds were absent from their old haunts. Possibly a migratory movement, due to the open weather of the winter of 1920-2I, may have been the cause of the absence of these birds, but our knowledge of this species is too fragmentary at present for us to hazard an opinion.

It must not be imagined that even now the ornithology of Spitsbergen has been worked out. The eastern side can be reached only in favourable seasons and late in the summer, and even then ice conditions vary from day to day, and the explorer may have to beat a hurried retreat or run the risk of being frozen in. Naturally its secrets can be disclosed only very gradually, and probably always very imperfectly. Even among the birds of the western coast we meet with problems which still await solution. We are still in doubt as to the status of the Snowy Owl (Nyctea nyctea), though the weight of evidence points to the probability of a few pairs being resident and more or less parasitic on the Ptarmigan. The long-tailed Skua (Stercorarias longicaudus) is also something of a problem, and the evidence with regard to its breeding not quite conclusive; and there is evidently a good deal still to be learned as to the Sanderling (Crocethia alba). It is hoped 
that the material brought back by the expedition will also help to clear up the vexed question as to the races of the Puffin (Fratercula arctica), as to which there is much division of opinion.

Some interesting observations bearing on the sexual selection theory were made by Julian $\mathrm{S}$. Huxley on the Red-throated Diver (Colymbus stellatus), confirming and extending the conclusions reached by him in his paper on the courtship of Podiceps cristatus (Proc. Zool. Soc., I9I4). After the birds have mated for the season, elaborate courtship ceremonies take place between the mated pair. At times the two birds swim near each other with necks arched and the open beak half submerged, uttering a special cry. At others, one bird will dive all round and about the other, sometimes emerging almost vertically from the water, as does Podiceps. The active performer in such cases may be either the male or the female.

There thus exist, as in the Crested Grebe, mutual nuptial ceremonies. The bird's bright colouring and special nuptial activities are connected with the bird's sexual life, but not secondary sexual characters-epigamic, but not sex-limited.

Of particular interest were the observations made on the period during which the birds are separating into pairs for the season. At this time, too, they indulge in special ceremonies, in which, however, rarely two, but usually three (or even four), individuals participate. The birds submerge the whole body with the exception of the breast; the neck is thrust slightly forward and the head held out, so that the appearance is that of a miniature Plesiosaur. In this attitude the birds plough through the water, as if running races. This ceremony was never observed later, and is certainly connected with the choice of mates. Most remarkable of all, it appears almost certain that tw̧o females may thus " compete" for a single male as well as vice versa. In any event, we have as a new feature that in this species the mutual or common nuptial activities of the two sexes extend even into the pairing-up period, where, if anywhere, sex-limited display and Darwinian sexual selection might be expected. This period was not observed in the previous work on Podiceps. The need for some theory of " mutual selection" to supplement the Darwinian theory of sexual selection is thus further emphasised.
Favourable opportunities for observing the nuptial activities of Phalaropes and Purple Sandpipers, in both of which reversed sexual coloration and habits occur, were unfortunately very few. It is, however, suggested that (I) the pressure of Arctic life acts as an encouragement to small size in the waders; (2) that, per contra, the short breeding season requires the eggs to be large, in order that their development may be hastened; this, in its turn, will limit the reduction in size of the female; (3) the female will therefore tend to be bigger than the male; (4) in almost all birds (excluding Raptcres) brighter colour of the male accompanies larger size. Presumably size, pigmentation, and psychological activity are all controlled together by the endocrine secretion of the gonad. It is thus probable that larger size of the female in these species will be associated with that type of metabolism which favours more intense pigmentation; (5) the more protectively coloured male could then more advantageously undertake incubation.

A discussion of this suggestion, however, would involve the handling of large bodies of evidence. It is, in any event, clear that the condition has developed from one in which both sexes were similarly coloured, and both shared the duties of incubation.

To sum up, we have here a series of nearly three hundred skins as well as about five hundred eggs, together with full diaries and field notes from members of the expedition. It is hoped that the reports on these collections will embody what is already known of the Spitsbergen and Bear Island group, and provide us with a dependable and handy manual on the birds of the archipelago. The com ing of the oil engine has already affected the fauna considerably, and probably will do so even more in the future, and it is important to record the changes of the last ten or fifteen years. Koenig's fine work is bulky and expensive, and a concise account of the bird life, embodying the results of the present expedition, would be a most valuable work of reference as well as a permanent memorial of what is perhaps the only serious ornithological work undertaken by English men or women in the Arctic since Mr. Henry Pearson's last voyage to Russian Lapland more than twenty years ago, with the sole exception of Miss Haviland's adventurous journey to the mouth of the Yenisei in rgr 4 .

\section{The Present Position of the Theory of Descent, in Relation to the Early History of Plants. ${ }^{2}$}

\section{By Dr. D. H. SсотT, F.R.S.}

$\mathrm{I}_{\mathrm{T}}^{\mathrm{T}}$ has long been evident that all those ideas of evolution in which the older generation of naturalists grew up have been disturbed, or, indeed, transformed, since the re-discovery of Mendel's work and the consequent development

\footnotetext{
1 Abridged from the presidential address delivered to Section K (Botany) of the British Association at Edinburgh on September 9 .
}

of the new science of genetics. Not only is the "omnipotence of natural selection" gravely impugned, but also variation itself, the foundation on which the Darwinian theory seemed to rest so securely, is now in question.

The small variations, on which the natural selectionist relied so much, have proved, for the No. 2709 , voL. I08] 